Fecha de recepción: abril 2021 Fecha de aprobación: mayo 2021 Fecha publicación: junio 2021
Investigations through the virtual
platforms of institutions that
develop biomaterials and their
relationship with sustainability

Marcelo Vicente da S. Júnior ${ }^{(1)}$, Theska Laila de F. Soares ${ }^{(2)}$ y Amilton José Vieira de Arruda ${ }^{(3)}$

\begin{abstract}
Recently, many companies and academic laboratories have emerged formulating new materials of biological origin for use in artifacts, in response to a scenario of unsustainability. This work aimed to investigate institutions that developed biomaterials, focusing on those that had real applications. In this sense, through social networks, several representative examples of the theme were found and analyzed from a qualitative perspective. In addition to an analysis of data collected through images and texts published on these platforms, it was also possible to map other data such as geographic origin, reach and engagement of the analyzed institutions. The results indicate that Instagram's artificial intelligence was valid to suggest different profiles that had to do with the research, such virtual platforms facilitate the perception and faster visualization of these biomaterials, however for a deeper analysis it was not so efficient, although they serve to disseminate and stimulate new initiatives in this context..
\end{abstract}

Keywords: Design - Biomimetics - Biomaterials - Sustainability - Circular Economy Digital Platforms

[Abstracts in spanish and portuguese at pages 196-197]

(1) Marcelo Vicente da Silva Júnior is Designer, $\mathrm{PhD}$ student and master in Design from the Federal University of Pernambuco (UFPE-BRA) with a period of mobility at the Faculty of Engineering of Porto (FEUP-PT), Bachelor of Design with qualification for Product project from the Federal University of Paraíba (UFPB-BRA). His research area is focused on the development of biomaterials and their social repercussions. marcelo.vicente@ufpe.br

(iD) https://orcid.org/0000-0002-1449-2726

(2) Theska Laila de Freitas Soares is PhD student, master and graduated in Design from the Federal University of Pernambuco (UFPE-BRA), has a specialization in Product and Interior Design from the FBV (BRA) partnership and the Istituto Europeo di Design (IED). She is the creative director at EDEN with professional experience in several areas of Design. She was a professor of Design at UNINASSAU (Recife-BRA) and a substitute for the Design department at UFPE (Agreste Campus). She has a strong focus on research in the areas of Biomimetics and Strategic Design. theska.soares@ufpe.br iD https://orcid. org/0000-0001-5493-1087 
(3) Amilton José Vieira de Arruda Graduation in Industrial Design Product Project by UFPE (1982), Master in Design and Bionics by IED in Milan (1992), Doctorate in Ricerca in Disegno Industriale - Ph.D by University of Milan Politecnico (2002) and postdoctoral in Design and Bionics at IADE European University UNIDCOM Lisbon (2018/2019). Since 1985 professor of the UFPE Design Course. He is currently associate professor IV. He coordinates the Research Group on Biodesign and Industrial Artifacts at UFPE. Organizer together with Edgard Blucher of the [DesignCONTEXTO] series design, culture and technology essays from the following books: (2017) 1. Design and Complexity; (2017) 2. Design and Social Innovation; (2018) 3. Design, Artifacts and Sustainable Systems; (2019) 4. Narratives and Languages in the creative process in Modeling and Prototyping (in press). Always with Edgar Blucher he organizes the series [designNATUREZA] essays on design, bionics and biomimetics with the following book: (2018) Methods and Processes in Bionics and Biomimetics: the technological revolution by nature. With the publisher Insigh in (2019) we launched the following title: Topics in Design: Biomimetics, Sustainability and New Materials; and recently with Blucher (2020) the Book: Design and Bionics. Carmelo Di Bartolo and Centro Ricerche IED: esperienze memorabili da 30 protagonisti. amilton. arruda@ufpe.br (iD) https://orcid.org/0000-0003-4551-4497

\section{Investigations through the virtual platforms of institutions that develop biomaterials and their relationship with sustainability}

The use of more natural materials in artifacts has accompanied humanity for most of its history. Only with the technological development, considered recent in comparison with the appearance of Man on the planet, that is, in the last decades, was it possible to create synthetic materials, artificially produced, that gained considerable space in the constructions and design projects (Lima, 2006). According to Moraes (2010), the technical-productive-factory capacity of the 20th century revolutionized habits and customs, but was unable to permeate ecological and environmental ethics, a factor that begins to be changed due to the growth of the environmental issue. In this way, it is possible to state that the products are almost always composed of various types of materials that impact the environment at different levels. Damages occurs since the extraction, and accumulates in the transformation of the raw material, use and disposal of the product by the consumer (Manzini and Vezzoli, 2011). In this sense, Thompsom (2015, p. 12) exposes the importance of the material selection process for sustainability, as it is the moment when the impacts that the product will cause to the environment are defined. Also for Manzini and Vezzoli (2011), when choosing the materials for the products, there can be a minimization of environmental damage by choosing materials that are more consistent with the resilience of the planet, and among those that bring less impact are natural materials, such as wood and those of vegetable origin, for example. For Lima (2006), with the growth of 
environmental problems, other more innovative approaches have been adopted for natural materials, rescuing their value for product design.

It is important to recognize that more and more this theme has been gaining adherents and the relevance and awareness of the theme of more sustainable materials for application in both architecture and design is growing. Manzini and Vezzoli (2002), point to environmental education as a pillar of sustainable development, as it contributes to integrating humanity into the environment and awakens in individuals and organized social groups the desire to participate in the construction of their citizenship. And this education can start from the initiative of some institutions, whether private or academic, to develop solutions for these new, more ecological materials, attracting the attention of society to discuss and promote this topic, that is, to be an example of this type of initiative. In this sense, social networks currently become important tools for the dissemination and knowledge of these new initiatives, mainly through the website of these institutions, Facebook and Instagram (notably the latter), there is a faster perception and greater reach due to a trend in the repost phenomenon, since education is also present through access to information. Therefore, this qualitative research sought to investigate profiles that developed biomaterials, initially through the Instagram platform, in order to understand how social networks can support the investigation of these biomaterials proposals; as well as analyzing the interaction with these institutions. In the beginning, profiles that dealt with the Do It Yourself (DIY) of biomaterials would be searched, however, after analyzing several identified profiles, it was observed that some researches were in the initial stages of experimentation. Therefore, among those options, those that evolved and advanced to such an extent that they actually created materials that could be certified to enter the market were privileged, offering concrete applications of the developed biomaterial.

\section{Biomaterials and Biomimetics}

Nature operates with an enviable efficiency for any machine ever built by man, be it whales and penguins that dive under the water without diving equipment; dragonflies that exceed the maneuverability of the best helicopters; ants that can carry the equivalent of hundreds of pounds; hummingbirds that cross the Gulf of Mexico with the equivalent of $3 \mathrm{ml}$ of fuel, among other countless examples of this efficiency of nature that is the result of an evolution that, over time, made them more able to survive. Therefore, observing how nature operates in the creation of its species, whether plants, animals or minerals, this same method can be transposed in the development of products, systems, constructions and even services, because the "criteria" observed in living beings more adapted, can serve as a basis for the development of more efficient solutions (Benyus, 1997). And that is what Biomimetics is about, a science that studies the models of nature and then imitates them, is inspired by them or their processes to solve human problems. According to Santos (2010), it also collaborates with the philosophy of environmental design, which has a multidisciplinary vision where many industrial sectors can replace the traditional method of design and production of consumer goods with the "method" of nature that is much more bal- 
anced and less costly for the environment. According to Soares (2016), Biomimetics has an interdisciplinary approach that brings together: nature and technology, biology and innovation, life and design. In practice, it seeks to bring the wisdom of time-tested life by providing valuable information for human solutions that create favorable conditions for life; sustainable creations by borrowing environmental insights and strategies, or seeks to be a connection that helps to fit, align and integrate the human species in the Earth's natural processes (See Figure 1).

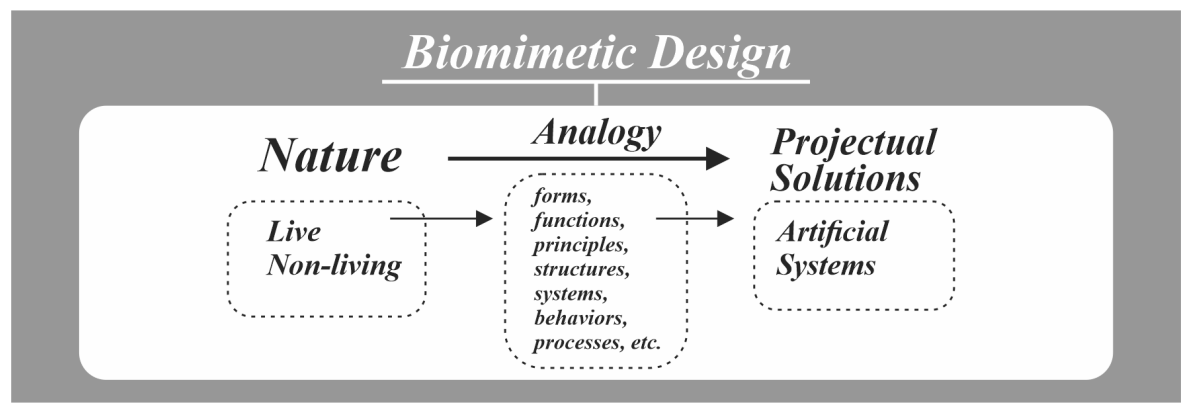

Figure 1. Scheme of Biomimetic Design. Source: Prepared by the authors.

In this way, one can consider the biomaterials formulated by man as an artificial biomimetic artifact, because they are imitating this characteristic of nature's own construction materials, which are biodegradable, compostable and do not cause damage to the environment. From the moment that it is intended to formulate artificial materials that behave with such characteristics, for the sake of sustainability, nature itself is being emulated. In this respect, a product is classified as biodegradable when its decomposition is fast compared to traditional products. In addition, it needs to be absorbed quickly by nature, generating less environmental impacts. In this way, biodegradable is all that is natural enough to degrade, undo, rot, easily and naturally, and become part of the earth again, without causing problems or leaving any residue, in other words, it is the one that is capable of being decomposed by biological agents (microorganisms). Compostable products are biodegradable, but much better for nature, as they degrade at a much faster rate and are rich in nutrients for the earth. The disaggregation time for a compostable product can vary from 2 weeks to 6 months. In ecology, composting refers to the biological process that consists in allowing fermentation and decomposition of organic residues (agricultural, forest, domestic or urban), mixed or not in vegetal soil, to obtain a material rich in nutrients and minerals in which the compost will be used as a natural fertilizer (Example: composting faeces). 
The circular economy is also an important concept for the topic of biomaterials, it is based on the principles of waste and pollution elimination, maintenance of products and materials in use and regeneration of natural systems. The economic system inherited from industrial revolutions, over the years, was based on a linear strategy, based on extracting, producing and discarding, so there is an urgent need to reinvent the way business is thought in order to evolve from one linear thinking model for a systemic, fundamental to innovate towards a regenerative production and consumption. Only in this way can businesses be placed at the service of generating positive social, environmental and economic impacts for society (Circular Economy 100, 2017, p. 4) (See Figure 2).

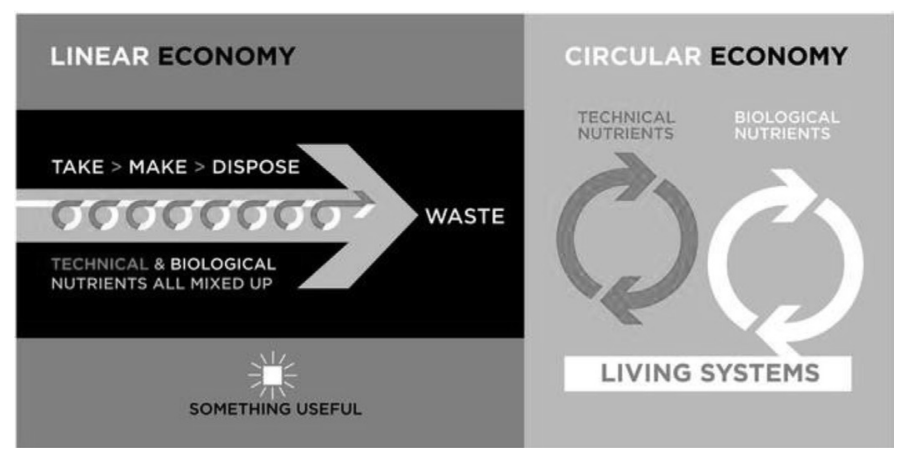

Figure 2. Linear Economy x Circular Economy. Source: Ellen MacArthur Foundation (2017).

The search for restorative perspectives, which aim to provide future generations with means for sustainable development, through the transformation of waste into resources is notorious (Smol, Kulczycka, Avdiushchenko 2017). When biomaterials of industrial residues are developed, for example, you collaborate with this thought because, being made of natural materials, they are biodegradable, without toxic chemicals to animals and humans and that can even be beneficial for the soil, such as compostables, one thinks also in the cycle, as its disposal does not have a negative impact on the environment.

Biomaterials can also be considered eco-materials, so it is important to briefly describe the 10 characteristics that allow a good framing of the problem of eco-materials (Arnal et al., 2008). Are they:

1. $\mathrm{CO}^{2}$ Absorbing Material: The choice of a material that actively participates in the solution of some of the most complicated current problems. The mitigation of global warming is the best option that construction can give to the environment. 
2. Sustainable Material: Using the raw materials that nature offers us in an inexhaustible way, we do not condition the future of our reserves.

3. Recyclable Materials: The destination of a recyclable material found in reuse, does not end at the landfill.

4. Recycled Material: Avoids the contamination and energy consumption necessary for the new manufacture of the same material, consequently the amount of waste is reduced.

5. Compositive Purity: The rawer materials are needed to obtain a material, the more complicated it is to separate and recycle it.

6. Incorporated Energy: In addition to the initial energy costs (extraction, transportation, manufacturing ...), it is important to understand the energy dependence of the material throughout its life cycle (thermal inertia; maintenance, breaks and wear; possibility of being recycled or reused).

7. Degree of Industrialization: Only for very small-scale projects is the use of artisanal material that requires a lot of labor and the intensive use of resources on the job (water and energy) justified. In all other projects, industrial materials should be used where there is a controlled consumption of resources and energy.

8. Healthy materials: Avoid using products that may affect the health of the manufacturer, the user and the worker in the recycling process. Especially with regard to toxic or carcinogenic particles.

9. Maintenance requirements: Low maintenance materials favor the user's comfort and reduce the use of paints, lubricants and varnishes.

10. Materials with ecological certification: Few materials have certification that guarantees a good use of resources, those that have it deserve privileged treatment.

\section{Biomaterials Cases}

Next, we will analyze some cases of institutions that develop biomaterials whose indication was suggested by Instagram's artificial intelligence, through the indication of profiles that are related to the main search, which in this case occurred by researching institutions that develop biomaterials, and it was automatically received indications of several similar profiles.

In each profile, the name, place of origin / headquarters, number of followers, and data about the material were sought, such as biodegradability, the type of material used, and the processes it goes through; in order to obtain a global understanding of the productive dynamics. In addition, the interaction with the institutions took place through a brief questionnaire to understand the dynamics of the project, the background of the development team, and whether Instagram enabled promising networking. It was also analyzed the time it took the profile to return the contact, and if the proposal was properly understood just by analyzing the digital platforms. The questions sent were as follows: How 
many people participate in this project, and what are their expertise? What infrastructure is necessary for the project development? How much time does it take to develop this project? Did the profile at Instagram help to publicize the research and make promising networking for investments in the project?

\section{Shell Homage (Germany/Egypt)}

With the objective of developing a material with the residues of the food industry, and in dialogue with the circular economy, the designer Rania Elkalla founded Shell Homage. The material developed is a composite of nut and egg shells, natural additives and vegetable resin. The properties of this material composition can be controlled using the production method, resulting in rigid, translucent, opaque materials, as well as a malleable structure. Its useful life is extended by being protected from UV rays and used in dry environments. The advantage of large-scale production is pointed out because, on a smaller scale, it spends more energy and time, not compensating for production. The proposal dialogues with the demands for sustainability, and highlights the important role of the designer in the material selection stage. In this project there is a great contribution to the circular economy, considering its biodegradable and compostable nature (providing minerals to the soil).

According to Ghada Abdel-Kader (2021), Shell Homage was the gold winner in the most beautiful solution category of Beyond Plastic awards 2020, bronze prize in design for society and eco-sustainable design category from the European Product Design award 2019; and also earned the Recycling Design Award and the Green Product Design Award in 2019. Currently the company is headquartered in Germany and Egypt. There are about 3 thousand followers on Instagram, and when accessing the profile, attention is paid to the use of highlights to locate the reader of relevant products, publications, processes and topics. The entire production process of the material is detailed and illustrated, making understanding more accessible. Regarding the interaction with the company, there was a first contact prior to this research (18/06/2020 at 21:25h GMT-3) where an experimental material developed by the researcher was shared, the page returned in less than 20 minutes. On the second contact, the page returned in 01 days, and asked the researchers to contact them by email, but did not return until the end of this research (See Figure 3). 


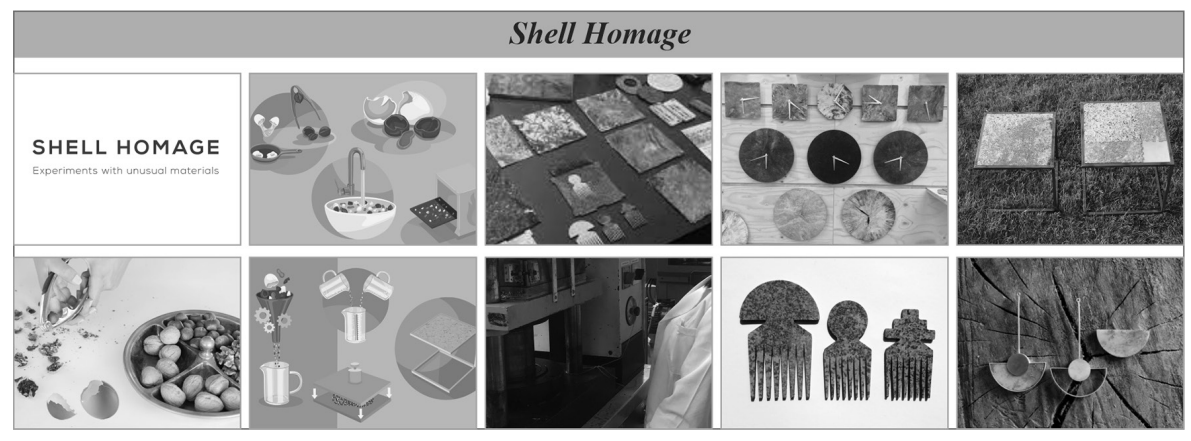

Figure 3. Compilation of images showing composition, process and some applications of the Shell Homage material. Source: (http://shellhomage.com/)

\section{Miyuca (Italy)}

With the main objective of generating alternatives to fossil-based materials, Italian designer Jasmin Castagnaro founded Miyuca in 2015, and developed a material based on leaves that fall from trees in the fall. The laboratory incorporates manual work, sustainability and design; the leaves are collected and separated according to their color and type, then they are crushed, and in sequence, mixed with natural additives and biological resins. The mixture is introduced into a mold and undergoes the curing process. In addition to the composition with leaves, in collaboration with German partner companies, a variation with a luminous effect was produced due to the use of salt containing natural ingredients such as mallow, rose petals and peppers. The initiative dialogues with the artisanal process of making artifacts, and uses metal as a way to reduce the use of plastic implements. In this sustainable perspective, the company uses a bioresin with a lower carbon footprint and highlights that through a "green" chemical process, sustainable materials and efficient manufacturing, there is energy conservation, reducing the emission of greenhouse gases. In addition, plastic is not used in packaging, it only uses cardboard and paper. The material suggests that for better durability, do not expose it excessively to UV rays and be used in indoor areas.

In 2019 the company was nominated for the German Design Award, and selected for the Green Product Award. In addition to the awards, it already has a CE certificate, showing the current capacity and the potential for commercial expansion in European territory. It is possible to contact Miyuca through four channels, Instagram being the most widespread with almost 2 thousand followers. The written content of the institutional page favors the understanding of the audiovisual content of Instagram and Facebook. Until the end of this article, the page did not return the contact (See Figure 4). 


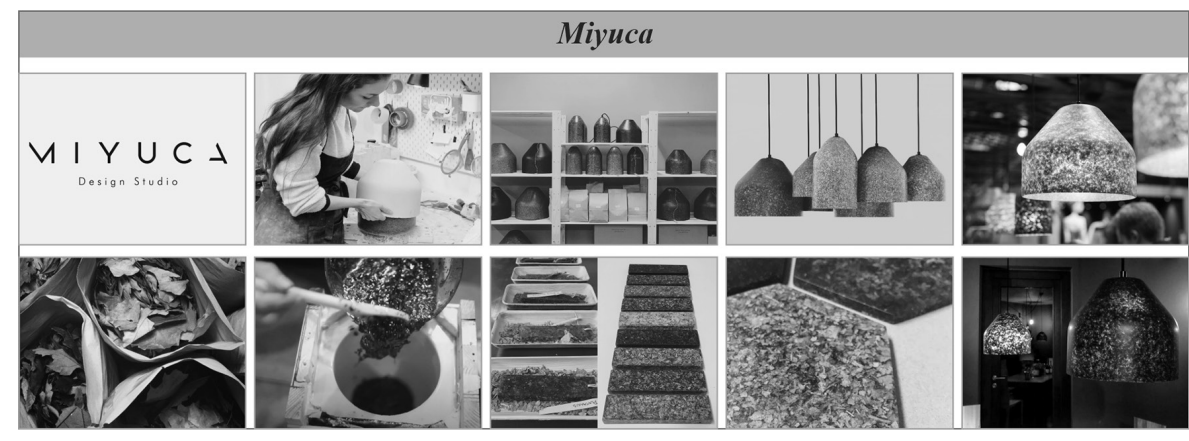

Figure 4. Compilation of images showing composition, process and some applications of the Miyuca material. Source: (https://www.instagram.com/miyucadesignstudio/)

\section{HighSociety (Italia)}

The Italian design studio Highsociety was founded in 2015 by craftman Johannes Kiniger and designer Giulia Farencena Casaro, in order to combine technology and Craftmanship. The initiative focuses on innovation in materials, specifically in the upcycling of waste from hemp, wine and tobacco. In an interview with VegComnomist (2019) the studio exposes the raw material acquisition process, in which they collect "wine waste, whilst tobacco (cultivated without harmful additives), and cultivate hemp to supply local wellness businesses with essential oils, and use the leftovers to create the hemp lampshade". The High Society's virtual page points out that for the production of the Highlight luminaire the residues are mixed with biodegradable binder; the mold with the material undergoes a high compression, resulting in trapezoidal shapes. Finally, the luminaires are sealed with natural carnauba wax, generating protection against moisture. The second highlight is the Senilia luminaire, which combines technology with social action. In an interview with Jennifer Hahn (2019) Johannes points out the combination of handcrafting and extrusion technique; using coffee and beer residues as inputs for the body and ceramics for the manufacture of the light bulb holder, reinforcing the totally recyclable and non-polluting character. The social aspect of the project is to support the initiative against chemical dependency, by donating a portion of the value of each lamp sold. In addition to working with Hemp, wine and tobacco waste, the studio also launched a line of cement tiles collection dyed with agri-food waste from wine.

Just like on Instagram, the institutional website also contextualizes the reader about the importance of actions in favor of sustainability, reinforcing the brand's values. In addition, the page uses the "selected press" section and exposes the most relevant interactions. A criticism in relation to the seizure of information is the need to access several pages of the "selected press" for the global understanding of the project, whoever accesses it would 
benefit from more direct information, for example, organized in a session of the website or in a highlight (Instagram). About the contact, there was no response until the submission of this article (See Figure 5).

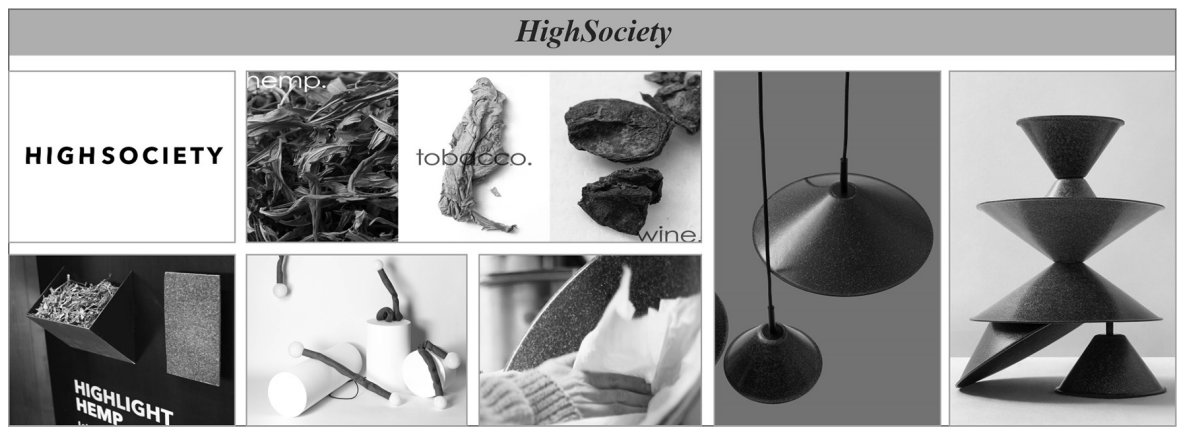

Figure 5. Compilation of images showing composition, process and some applications of the Highsociety material. Source: (https://high-society.it/highlight)

\section{Mush.eco (Brazil)}

Mush.eco is a Brazilian company that created a material based on mycelium, which is a material with a vegetative part of fungus that uses substrates from plant residues to grow. It arose from a research project at the Fermentations Laboratory of the Bioprocess Engineering and Biotechnology course, at the Federal Technological University of Paraná. In this same institution, the company was incubated and developed the project for residual agricultural reuse, using corn stalks and / or sugarcane bagasse combined with microorganisms to aggregate the residual particles and thereby produce the material. The process results in a versatile product that can be used in packaging, in civil engineering and for the purpose of acoustic comfort; thus combining design, functionality and sustainability. The team is composed of Eduardo Bittencourt, a bioprocess and biotechnology engineer; Leandro Inagaki, chemical engineer; Antonio Carlos, production engineer; and two designers.

The material is partially resistant to water and fire. Because they are produced with $100 \%$ natural and biodegradable raw material, the products can be discarded in nature after use, returning nutrients to the soil. The commercialization started in April 2021, four pieces of $30 \mathrm{~cm}$ of the material costs $\mathrm{R} \$ 90.00$, and the company argues that the acquisition of this material supports the environment, agribusiness and the development of research and 